\title{
Pareto-optimal alloys
}

Bligaard, Thomas; Johannesson, Gisli Holmar; Ruban, Andrei; Skriver, Hans Lomholt; Jacobsen, Karsten Wedel; Nørskov, Jens Kehlet

\section{Published in:}

Applied Physics Letters

Link to article, DOI:

$10.1063 / 1.1631051$

Publication date:

2003

Document Version

Publisher's PDF, also known as Version of record

Link back to DTU Orbit

Citation $(A P A)$ :

Bligaard, T., Johannesson, G. H., Ruban, A., Skriver, H. L., Jacobsen, K. W., \& Nørskov, J. K. (2003). Paretooptimal alloys. Applied Physics Letters, 83(22), 4527-4529. https://doi.org/10.1063/1.1631051

\section{General rights}

Copyright and moral rights for the publications made accessible in the public portal are retained by the authors and/or other copyright owners and it is a condition of accessing publications that users recognise and abide by the legal requirements associated with these rights.

- Users may download and print one copy of any publication from the public portal for the purpose of private study or research.

- You may not further distribute the material or use it for any profit-making activity or commercial gain

- You may freely distribute the URL identifying the publication in the public portal

If you believe that this document breaches copyright please contact us providing details, and we will remove access to the work immediately and investigate your claim. 


\title{
Pareto-optimal alloys
}

\author{
Thomas Bligaard, Gisli H. Jóhannesson, Andrei V. Ruban, Hans L. Skriver, \\ Karsten W. Jacobsen, ${ }^{\text {a) }}$ and Jens K. Nørskov \\ Center for Atomic-scale Materials Physics, Department of Physics, Technical University of Denmark, \\ DK-2800 Lyngby, Denmark
}

(Received 14 August 2003; accepted 25 September 2003)

\begin{abstract}
Large databases that can be used in the search for new materials with specific properties remain an elusive goal in materials science. The problem is complicated by the fact that the optimal material for a given application is usually a compromise between a number of materials properties and the cost. In this letter we present a database consisting of the lattice parameters, bulk moduli, and heats of formation for over 64000 ordered metallic alloys, which has been established by direct first-principles density-functional-theory calculations. Furthermore, we use a concept from economic theory, the Pareto-optimal set, to determine optimal alloy solutions for the compromise between low compressibility, high stability, and cost. (C) 2003 American Institute of Physics.
\end{abstract}

[DOI: $10.1063 / 1.1631051]$

It would be important if one could establish a "materials informatics" approach in searching for new materials. If ideas for new materials could be generated by suitable searches in databases, one could decrease the number of expensive experiments that need to be done. One approach in this direction has been the "Materials Selector" introduced by Ashby. ${ }^{1}$ Here selection of a material for a particular application is made on the basis of a database of existing materials. When it comes to the prediction of new materials including compositions and structures that have not yet been synthesized and tested there are presently very few approaches. One simple example is the very successful "Miedema model" 2 which relates alloy heats of formation to two parameters characterizing each metallic element in the periodic table.

The underlying problem in any materials informatics approach is that even though a number of materials properties are now assembled, there are still very few experimental data compared to the vast number of possible material combinations. One way of increasing the amount of data in materials science is to rely on first principles density functional calculations. The calculations now have a level of accuracy, which is often comparable to experiments, in particular when the purpose is to describe variations from one system to the next. ${ }^{3-5}$ We have used our density functional calculations to evaluate the equation of state (the relation between energy and volume of the material) for 64149 different alloys with up to four components.

For each alloy we perform first-principles total-energy calculations for at least four different unit cell volumes and, subsequently, fit the energy-volume curve to an equation of state. The calculations have been performed within an linear muffin-tin orbital atomic sphere approximation (LMTOASA) implementation ${ }^{6}$ of the generalized gradient approximation $^{7}$ for the exchange and correlation energy (see Ref. 5 for details). A database of the derived materials parameters: lattice constants, heats of formation, and bulk moduli for all the calculated alloys is available at http://

${ }^{a)}$ Electronic mail: kwj@fysik.dtu.dk
www.fysik.dtu.dk/CAMPMDB/QuaternaryAlloys/.

The database contains 64149 out of a total of 192016 possible four (or less)-component alloys in the face-centered cubic and body-centered cubic structures with four atom unit cells and, therefore, we cannot be sure that all interesting alloys are included. However, the database was made in a search for the most stable alloys ${ }^{5}$ and since these are also the alloys that may most likely be synthesized and remain unchanged afterwards, the database should contain some of the most interesting alloys from an application point of view.

Given the database, the question is how one may use it to search for new materials. We will illustrate this by searching for the alloys that have the smallest compressibility. A low compressibility by itself is interesting, since it means that the material is very hard, ${ }^{8}$ but it is also interesting from other points of view. It has, for instance, been shown (Ref. 1) that there is a monotonic relationship between the Young's modulus and the thermal expansion coefficient, and the Young's modulus is approximately equal to the inverse compressibility for most metals. A low compressibility is therefore a good sign of a low thermal expansion coefficient, something that is very sought after, for instance, as back plates for power electronics. ${ }^{9}$ The set of ordered metallic alloys is just a subset of possibly useful materials for making back plates. Other materials, such as carbides, nitrides, and diamond can have the wanted high thermal conductivity, low thermal expansion, and high stability. We have not considered such materials in the present study, as these materials often arrange themselves in much more complicated structures than the intermetallic alloys, whereby it becomes computationally more demanding to make calculations of predictive quality.

It is a simple task to find the elementary metal in the database with the lowest compressibility. It is Os, which was recently shown both theoretically and experimentally ${ }^{10}$ to be less compressible than even diamond at elevated pressures. Os is extremely expensive, however, and Os back plates on power electronics is not a viable option. The question is now how much one is willing to pay for a given level of com- 


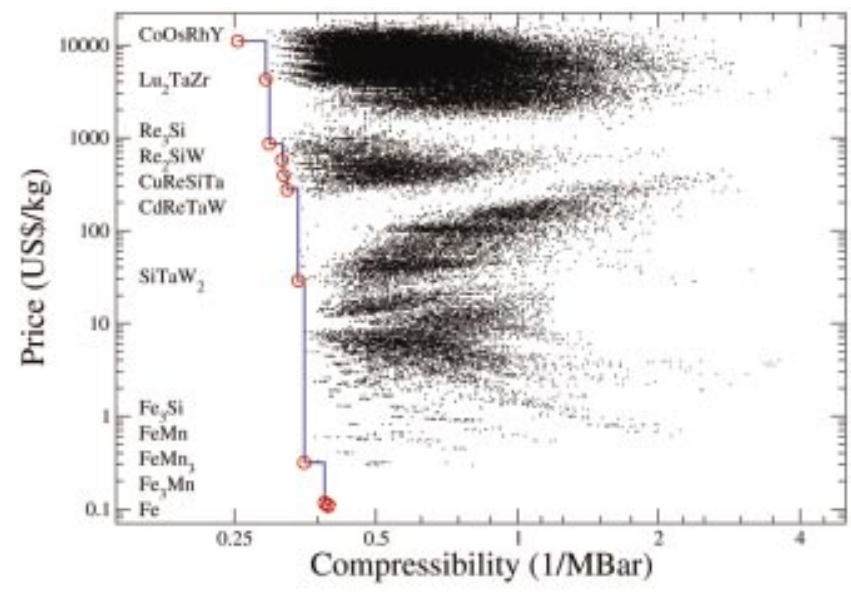

FIG. 1. (Color) Two-dimensional Pareto optimization: Theoretical compressibilities for 64149 four-component alloys including the Pareto-optimal set of alloys with respect to low price and low compressibility.

pressibility. If there is a way of a priori answering this question, then one can effectively combine the two variables, cost, and compressibility into one variable, thereby reducing the dimensionality of the problem to an optimization problem in one dimension. This closely resembles the approach by Ashby (see Ref. 1), who on the basis of engineering knowledge and dimensional analysis for many problems can reduce the initial variables to so-called materials indices, which can then be optimized. Sometimes, however, there is no a priori way of weighting the importance of the individual properties or materials indices against each other. This is an example of a multiobjective optimization problem, which is often discussed in the economics literature, where one is trying to maximize the utility of a given investment while minimizing the price. There, a common solution is to use the Pareto-optimal set, as defined by the influential neoclassical economist Vilfredo Pareto in the beginning of the last century. ${ }^{11}$ A discussion of Pareto-optimization in more dimensions is given in Ref. 12. In multiobjective optimization, there is normally not one single solution, which is optimal in all respects. Still some solutions are superior to others. These are called the nondominated solutions and are defined as those for which it is impossible to improve one property, without making another property worse. The Pareto-optimal set is the set of all nondominated solutions.

In Fig. 1 we present the 64149 alloys as small dots. They are positioned according to their compressibility along the $x$ axis and their cost along the $y$ axis. The alloy prices are determined from the 1998 commodity prices of the pure elements ${ }^{13}$ from which they are made. The cost of elemental extraction and purification is thus included, whereas the actual expenses in making the alloys afterwards are neglected, as these expenses would depend on the actual production process (method, quantity, rate, etc.). The alloys, which are Pareto-optimal with respect to low cost and compressibility are connected by a solid line. This line, commonly called the Pareto-front, bounds the set of alloys "from below" and therefore contains the most interesting solutions: given an alloy, which is not in the Pareto-optimal set it is always possible to find an alloy in the set, which is both cheaper and has lower compressibility. The Pareto-front in Fig. 1 immediately suggests why iron and iron alloys have found such Downloaded 01 Apr 2010 to 192.38.67.112. Redistribution subject

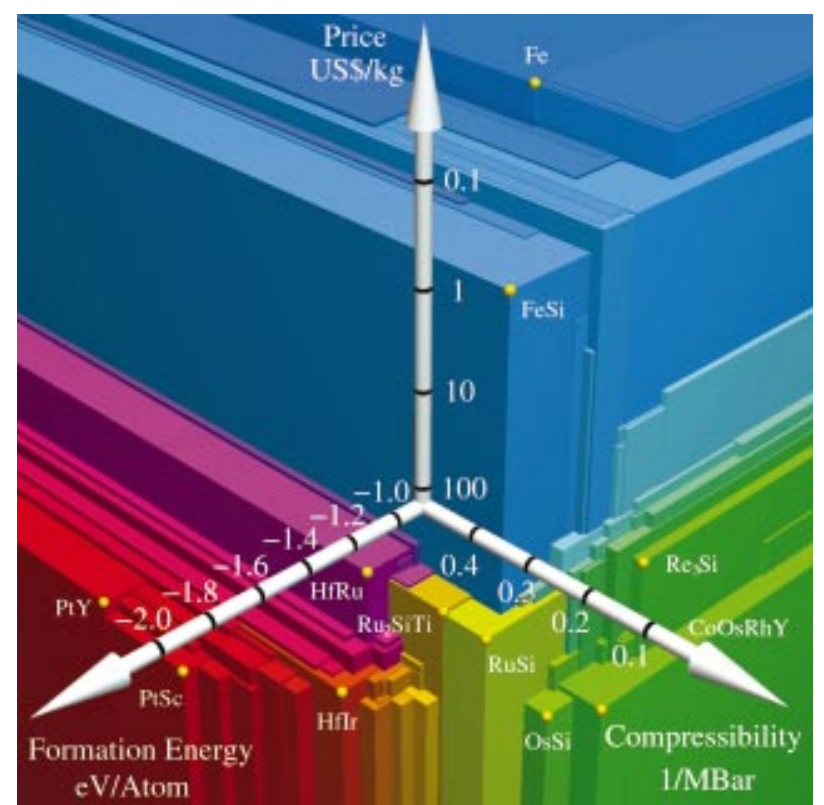

FIG. 2. (Color) Three-dimensional Pareto optimization: Pareto-optimal set of alloys with respect to high stability, low compressibility, and low price.

widespread use for applications where high hardness (low compressibility) is desired at a reasonable price. The iron containing alloys are two orders of magnitude less expensive than the cheapest improvement-the tungsten and tantalum containing alloys. To decrease the compressibility even further, one has to add rhenium or eventually osmium, whereby the alloys become another one or two orders of magnitude more expensive, respectively.

Figure 2 shows a Pareto-optimization of the alloy database with respect to high stability as well as low price and low compressibility. In this figure all the dominated solutions have been removed and the nondominated solutions are depicted as boxes. The corner of each box is placed at the point in a three-dimensional coordinate system, which corresponds to the formation energy, compressibility, and cost of that alloy. The boxes are colored according to the qualities of the given alloy: The more negative the formation energy the more red the color, the lower the compressibility the more green the color, and the less expensive and more blue the color. A table with names, formation energy, compressibility, and price for each of the 82 Pareto-optimal alloys in Fig. 2 is available at http://www.fysik.dtu.dk/CAMPMDB/ QuaternaryAlloys/. The Pareto optimal set as depicted in Fig. 2 reproduces some well-known characteristics of alloys. Focusing on the regions where a single parameter is fully optimized we see that the most stable alloys are obtained by combining late and early transition metals like PtY or PtSc because the formation of a common half-filled $d$ band from an almost filled and an almost empty one gives the largest stability. ${ }^{14}$ The alloys with the lowest compressibility typically contain Os or other transition metals from the central region of the periodic table where the compressibility of the pure elements is low again due to the electronic $d$ band, and the cheapest materials are as already mentioned, not unexpectedly the iron-containing compounds. However, there is also interesting new and less obvious information in the data set. For example the strong presence of silicides (for example, RuSi) points to some interesting possibilities for AIP license or copyright; see http://apl.aip.org/apl/copyright.jsp 
midrange cost materials with low compressibility and high stability in cases where the potential silicon oxidation problem can be controlled.

Although finding the Pareto-optimal set in multiobjective optimization of more than three properties does not pose any further challenge, it does become more difficult to depict the results graphically. When you only have a few materials to choose from, it might not make a big difference, how you pick the optimal ones. There will be very few, and you will know what to look for. When designing very specific materials on the other hand, which have to fulfill many constraints, and when you may have millions or billions of materials to choose from it will make a very big difference which method is used to generate good compromises. We propose using Pareto-optimality as such a method in the future, where high-throughput experimental methods and much faster computers are going to vastly expand the number of new accessible materials.

The authors acknowledge support from Danish Center for Scientific Computing through Grant No. HDW-1101-05.
${ }^{1}$ M. F. Ashby, Materials Selection in Mechanical Design, 2nd ed. (Butterworth-Heinemann, Oxford, 1999).

${ }^{2}$ F. R. de Boer, R. Boom, W. C. M. Mattens, A. R. Miedema, and A. K. Niessen, Cohesion in Metals-Transition Metal Alloys (North-Holland, Amsterdam, 1988).

${ }^{3}$ W. Kohn, Rev. Mod. Phys. 71, 1253 (1999).

${ }^{4}$ P. Kratzer and M. Scheffler, Comput. Sci. Eng. 3, 16 (2001).

${ }^{5}$ G. H. Jóhannesson, T. Bligaard, A. V. Ruban, H. L. Skriver, K. W. Jacobsen, and J. K. Nørskov, Phys. Rev. Lett. 88, 255506 (2002).

${ }^{6}$ A. V. Ruban and H. L. Skriver, Comput. Mater. Sci. 15, 119 (1999).

${ }^{7}$ Y. Wang and J. P. Perdew, Phys. Rev. B 44, 13298 (1991).

${ }^{8}$ A. Y. Liu and M. L. Cohen, Science 245, 841 (1989).

${ }^{9}$ N. Faust, R. W. Messler, and S. Khatri, J. Electron. Mater. 30, 1276 (2001).

${ }^{10}$ H. Cynn, J. E. Klepeis, C.-S. Yoo, and D. A. Young, Phys. Rev. Lett. 88, 135701 (2002).

${ }^{11}$ V. Pareto, Manuale di Economia Politica (Societa Editrice Libraria, Milano, 1906); translated to English as: Manual of Political Economy (Macmillan, New York, 1971), p. 261.

${ }^{12}$ D. E. Goldberg, Genetic Algorithms in Search, Optimization and Machine Learning (Addison-Wesley, Reading, MA, 1989), pp. 197-201.

${ }^{13}$ U.S. Geological Survey report: Metal Prices in the United States through 1998; http://minerals.usgs.gov/minerals/pubs/metal_prices/

${ }^{14} \mathrm{~J}$. Friedel, in Physics of Metals, edited by J. M. Ziman (Cambridge University Press, Cambridge, 1969), p. 495. 